\title{
EVALUATION OF ORAL PREGABALIN IN TREATMENT OF PREMATURE EJACULATION
}

\author{
Mohamed Refaat Al-Naggar, Mohamed Dardiri EL Hariri, Abdulrahman Hefny Hashem
}

Dermatology, Venereology and Andrology, Faculty of Medicine - Al-Azhar University (Cairo)

Corresponding Author Abdulrahman Hefny

Hashem

01000522257

dr.banna77@gmail.com

\section{ABSTRACT}

Background: Premature ejaculation (PE) is the most common form of male sexual dysfunction. Treatment modalities include behavioral therapy and medical therapy. No therapy is approved by the FDA for treatment of PE. Pregabalin exerts a negative effect on sexuality by reducing central nervous excitatory transmission via sodium and calcium channel inhibition and potassium (k) channel activation and by unbalancing dopamine serotonine ratio. The aim of this work was to assess the efficacy and safety of oral on demand pregabalin in treatment of premature ejaculation (PE).Methods: This study was conducted on 96 married male patients with primary premature ejaculation (lifelong). All patients were recruited from the andrology outpatient clinic at Al-Azhar University Hospitals (Cairo).The patients were randomly assigned to three groups: Group A: This group included 36 patients. They will receive $150 \mathrm{mg}$ pregabalin $1-2$ hours prior to sexual intercourse. Group B: This group included 30 patients. They will receive $75 \mathrm{mg}$ pregabalin $1-2$ hours prior to sexual intercourse. Group C: This group included 30 patients, all of them received identical placebo capsules. All patient will be subjected to the following:Full history: including age, baseline estimated ILET, erectile dysfunction, medical diseases and medications. Local and general physical examination. Couples were encouraged to engage in coitus twice a week and record estimated intravaginal ejaculation latency time (perceived IELT OR PIELT) every time for 2 weeks and report any side effects suspected to be drug related. Results: There was no statistically significant difference between group $\mathrm{A}, \mathrm{B}$ and $\mathrm{C}$ regarding base PIELT. PIELT significantly increased after treatment in group A receiving 150 mg pregabalin. Patients in group B showed mild improvement in their PIELT after receiving $75 \mathrm{mg}$ pregabalin. This improvement was statistically significant. There was no statistically significant difference between Base PIELT and PIELT after treatment among group $\mathrm{C}$ patients. There was statistically significant difference between group $\mathrm{A}$ and $\mathrm{C}$ regarding after treatment PIELT. There was no statistically significant difference between group $\mathrm{B}$ and $\mathrm{C}$ regarding PIELT after treatment. Comparing post treatment ejaculatory time in different groups, PIELT significantly improved in group A rather than placebo group. This was not present in group B. There was significant improvement in PIELT of group A rather than group B. Conclusion: This is the first report of an oral pregabalin used for the treatment of $\mathrm{PE}$ in men. On demand oral pregabalin $150 \mathrm{mg} 1-2$ hours prior to sexual relation, looks to be effective pharmacotherapy of PE. The effect of pregabalin is minimal and may be augmented with higher daily doses. Longer-term safety studies, and those comparing pregabalin with on demand tramadol and dapoxetine are essential to determine the place of pregabalin in the treatment of this distressing condition.

Key words: Premature Ejaculation - Pregabalin - Evaluation.
INTRODUCTION

$\mathbf{P}$ remature ejaculation $(\mathrm{PE})$ is the most common form of male sexual dysfunction. Globally, between $20 \%$ and $40 \%$ of men, at some point in their lives, have reported complaint of $\mathrm{PE}^{(\mathbf{1})}$ 
Premature ejaculation (PE) may be classified characterized by early ejaculation in the majority of intercourse attempts with nearly every partner from the first sexual encounter onwards, whereas acquired PE develops at some point in a man's life after he has previously experienced normal ejaculation and may be linked to urological or psychological problems ${ }^{(2)}$

It is so difficult to get an accurate definition and diagnosis of premature ejaculation. Recently; The International Society of Sexual Medicine (ISSM) produced its guidelines of the diagnosis and management of PE. It postulated an evidence-based definition of PE and defined PE as "A male sexual dysfunction characterized by ejaculation which is always or nearly always occurs prior to or within 1 minute of vaginal penetration; and an inability to delay ejaculation on all or nearly all vaginal penetrations, and negative personal consequences, such as distress, bother, frustration, and/or the avoidance of sexual encounters", (3)

Premature ejaculation has been associated with erosion in sexual self-confidence and low sexual satisfaction in men and their female partners ${ }^{(4)}$

The Intravaginal Ejaculation Latency Time (IELT) is the time from vaginal intromission to intravaginal ejaculation ${ }^{(5)}$

Premature ejaculation up till now has no definitive etiopathology, investigation or effective treatment. The etiology of premature ejaculation has included a diverse range of biogenic and psychological theories. Most of these proposed etiologies are speculative and not evidence based ${ }^{(6)}$

Treatment modalities include behavioral therapy and medical therapy. No therapy is approved by the FDA for treatment of PE, A range of drugs is currently used by clinicians for the management of PE; antidepressants including Selective Serotonin Re-uptake Inhibitors (SSRIs), local anesthetic agents and phosphodiesterase type 5 inhibitors ${ }^{(7)}$

Pregabalin exerts a negative effect on sexuality by reducing central nervous excitatory transmission via sodium and calcium channel inhibition and potassium $(\mathrm{k})$ channel activation and by unbalancing dopamine serotonine ratio. Mofadinil used in as lifelong or acquired. Lifelong $\mathrm{PE}$ is treatment of narcolepsy, Act through activation of central dopaminergic and serotonin pathways. It showed good results in treatment of $\mathrm{PE}^{(\mathbf{8})}$

The aim of this work was to assess the efficacy and safety of oral on demand pregabalin in treatment of premature ejaculation (PE).

\section{SUBJECTS AND METHODS}

This study was conducted on 96 married male patients with primary premature ejaculation (lifelong). All patients were recruited from the andrology outpatient clinic at Al-Azhar University Hospitals (Cairo).

\section{Inclusion criteria:}

1. Patients with primary (lifelong) PE, with Ejaculation which always or nearly always occurs prior to or within about one minute of vaginal penetration according to The International Society for Sexual Medicine (ISSM) In August 2014.

2. Being married for at least 4 months, and in a stable relationship with regular sexual intercourse at least twice per week with a cooperative female partner.

\section{$3 . \quad$ Normal erectile function.}

\section{Exclusion criteria:}

1. Erectile dysfunction or other sexual dysfunction e.g. reduced sexual desire.

2. Major psychiatric or psychological illness.

3. Chronic medical disorders that may limit the usage of pregabalin.

4. Men receiving medications that could affect ejaculatory function or interact with pregabalin.

5. Sexual dysfunction in the female partner.

6. Secondary premature ejaculation.

7. Age less than 18 or more than 50 .

The patients were randomly assigned to three groups:

\section{Group A:}

This group included 36 patients. They will receive $150 \mathrm{mg}$ pregabalin $1-2$ hours prior to sexual intercourse.

\section{Group B:}

This group included 30 patients. They will receive $75 \mathrm{mg}$ pregabalin $1-2$ hours prior to sexual intercourse.

\section{Group C:}


This group included 30 patients, all of them received identical placebo capsules.

All patient will be subjected to the following:

1. Written concept; after explaining the nature of the study

2. Full history: including age, baseline estimated ILET, erectile dysfunction, medical diseases and medications.

3. Local and general physical examination.

4. Couples were encouraged to engage in coitus twice a week and record estimated intravaginal ejaculation latency time (perceived IELT OR PIELT) every time for 2 weeks and report any side effects suspected to be drug related.

Most guidelines state that stopwatch measured ILET should be the accepted method for ILET evaluation in clinical researches. However this method always associated with more performance anxiety which itself worsen the ILET. Also multiple researches proved that both stopwatch measured ILET and PILET are highly correlated $^{(9)}$

\section{STATISTICAL ANALYSIS}

The data were coded, entered and processed on computer using SPSS (version 18). The results were represented in tabular and diagrammatic forms then interpreted. Mean, standard deviation, range, frequency, and percentage were use as descriptive statistics. The following test was done: Student's t-test was used to assess the statistical significance of the difference between two population means in a study involving independent samples. Student's paired t-test was used to assess the statistical significance of the difference between two population means in a study involving paired samples. ANOVA (F test) For normally quantitative variables, to compare between more than two groups, and
Post Hoc test (LSD) for pairwise comparisons. Value was considered significant as the following: $\mathrm{P}>0.05$ : Nonsignificant. $\mathrm{P} \leq 0.05$ : Significant

\section{4-Results:}

Eleven cases of all patients received pregabalin (in both group A \& B) showed various side effects (16.6\%). They distribution were as follow; Eight out of thirty sex cases - group A (22.2\%).Three out of thirty cases - group B $(10 \%)$. Pregabalin was generally found to be well tolerated, with mild or no adverse effects. The experienced side effects are showed in Table $2 \& 3 \& 4$. There was no significant difference between ages in all groups. Table (1)

There was no statistically significant difference between group A, B and C regarding base PIELT. Table (2)

PIELT significantly increased after treatment in group A receiving $150 \mathrm{mg}$ pregabalin. Table (3)

Patients in group B showed mild improvement in their PIELT after receiving $75 \mathrm{mg}$ pregabalin. This improvement was statistically significant. Table (4)

There was no statistically significant difference between Base PIELT and PIELT after treatment among group $\mathrm{C}$ patients. Table (5)

There was statistically significant difference between group $\mathrm{A}$ and $\mathrm{C}$ regarding after treatment PIELT. Table (6)

There was no statistically significant difference between group $\mathrm{B}$ and $\mathrm{C}$ regarding PIELT after treatment. Table (7)

Comparing post treatment ejaculatory time in different groups, PIELT significantly improved in group A rather than placebo group. This was not present in group B. There was significant improvement in PIELT of group A rather than group B. Table (8)

Table 1 Comparison between groups A, B and C regarding age.

\begin{tabular}{|l|l|l|l|l|l|l|}
\hline \multicolumn{2}{|l|}{} & Group A & Group B & Group C & F. test & P. value \\
\cline { 1 - 6 } $\begin{array}{l}\text { Age } \\
\text { (years) }\end{array}$ & Range & $23-44$ & $22-42$ & $22-42$ & 0.582 & 0.561 \\
\cline { 2 - 5 } & Mean \pm SD & $32.22 \pm 5.96$ & $30.76 \pm 6.52$ & $32.30 \pm 6.39$ & & \\
\hline
\end{tabular}


Table 2 Comparison between groups A, B and C regarding base PIELT.

\begin{tabular}{|l|l|l|l|l|l|l|}
\hline \multicolumn{2}{|l|}{} & Group A & Group B & Group C & F. test & P. value \\
\hline $\begin{array}{l}\text { Base } \\
\text { PIELT }\end{array}$ & Range & $0.25-1$ & $0.50-1$ & $0.50-1$ & & \\
\cline { 2 - 8 } & Mean \pm SD & $0.69 \pm 0.23$ & $0.77 \pm 0.19$ & $0.73 \pm 0.22$ & 3.875 & 0.194 \\
\hline
\end{tabular}

Table 3 Comparison between Base PIELT and PIELT after treatment regarding group A.

\begin{tabular}{|l|l|l|l|l|l|}
\hline \multicolumn{2}{|c|}{} & Base PIELT & $\begin{array}{l}\text { PIELT after } \\
\text { treatment }\end{array}$ & T. test & P. value \\
\hline \multirow{2}{*}{ Group A } & Range & $0.25-1$ & $0.75-3$ & $7.127-$ & 0.000 \\
\cline { 2 - 4 } & Mean \pm SD & $0.69 \pm 0.24$ & $1.22 \pm 0.51$ & & \\
\hline
\end{tabular}

Table 4 Comparison between Base PIELT and PIELT after treatment among group B.

\begin{tabular}{|l|l|l|l|l|l|}
\hline \multicolumn{2}{|c|}{} & $\begin{array}{l}\text { Base } \\
\text { PIELT }\end{array}$ & $\begin{array}{l}\text { PIELT after } \\
\text { treatment }\end{array}$ & T. test & P. value \\
\hline \multirow{2}{*}{ Group B } & Range & $0.50-1$ & $0.50-2$ & -1.439 & 0.016 \\
\cline { 2 - 4 } & Mean \pm SD & $0.77 \pm 0.18$ & $0.87 \pm 0.35$ & & \\
\hline
\end{tabular}

Table 5 Comparison between Base PIELT and PIELT after treatment among group C.

\begin{tabular}{|l|l|l|l|l|l|}
\hline \multicolumn{2}{|c|}{} & Base PIELT & $\begin{array}{l}\text { PIELT after } \\
\text { treatment }\end{array}$ & T. test & P. value \\
\hline $\begin{array}{l}\text { Group } \\
\text { C }\end{array}$ & Range & $0.50-1$ & $0.50-1$ & -1.9 & 0.06 \\
\cline { 2 - 5 } & Mean \pm SD & $0.73 \pm 0.217$ & $0.78 \pm 0.215$ & & \\
\hline
\end{tabular}

Table 6 Comparison between group A and C regarding after treatment PIELT.

\begin{tabular}{|l|l|l|l|l|l|}
\hline \multicolumn{2}{|l|}{} & Group A & Group C & T. test & P. value \\
\hline $\begin{array}{l}\text { PIELT after } \\
\text { treatment }\end{array}$ & Mean + SD & $1.22 \pm 0.51$ & $0.78 \pm 0.22$ & 4.42 & 0.000 \\
\hline
\end{tabular}

Table 7 Comparison between group B and C regarding PIELT after treatment.

\begin{tabular}{|l|l|l|l|l|l|}
\hline \multicolumn{2}{|c|}{} & Group B & Group C & T. test & P. value \\
\hline $\begin{array}{l}\text { PIELT after } \\
\text { treatment }\end{array}$ & Mean \pm SD & $0.87 \pm 0.35$ & $0.78 \pm 0.21$ & 1.217 & 0.229 \\
\hline
\end{tabular}

Table 8 Comparison between group A and B regarding PIELT after treatment.

\begin{tabular}{|l|l|c|c|c|c|}
\hline \multicolumn{2}{|l|}{} & Group A & Group B & T. test & P. value \\
\hline $\begin{array}{l}\text { PIELT after } \\
\text { treatment }\end{array}$ & Mean \pm SD & $1.22 \pm 0.51$ & $0.87 \pm 0.35$ & 3.170 & 0.002 \\
\hline
\end{tabular}

\section{DISCUSSION}

Premature ejaculation (PE) is the most common sexual dysfunction, with the majority of $\mathrm{PE}$ patients remaining undertreated. There are limited data available regarding potential underlying mechanisms and long-term outcomes of treatment options. To date, the U.S. Food and Drug Administration (FDA) has not approved any medications for the treatment of PE. As such, 
any medical treatments are currently administered off-label, and patients must therefore be counseled as to the risks and benefits of therapy. Treatments must additionally be individualized according to the type of PE complaint, as well as patient and partner preferences.

In this study we assessed the efficacy and safety of on demand oral pregabalin in treatment of PE.

The mean baseline PIELT values were similar across the treatment groups, with subjects having on average, a mean PIELT from their baseline attempts ranging between 0.25 minutes and 1 minutes.

Our patients are men in sexual active age (2244) years, all of them are in stable marriage, the mean PIELT should be less than one minute. Age distribution and mean PIELT are similar in all groups.

Although most of the clinical trials use the stopwatch IELT as an evaluation tool, we choose the PIELT as an evaluation parameter in this study. This is due to several factors;

- Most of the andrologist accept the PIELT as an evaluation method for PE in their practice.

- Stopwatch IELT always accompanied with performance anxiety that may affect patient IELT. It is unpractical and difficult to use.

- Recent multiple researches proved that both methods are markedly similar

- The fraction of error in evaluating base IELT will be the same in the post treatment IELT, as the measuring method is identical. ${ }^{(9)}$

Group A showed significant increase in the PIELTS from a mean of $0.69 \pm 0.24 \mathrm{~min}$ pretreatment to $1.22 \pm 0.51 \mathrm{~min}$ two weeks after treatment $(\mathrm{P}<0.000)$. Group B Showed significant increase in PIELTS pre and post treatment $(0.77+0.18, \quad 0.87+0.35)$ respectively, however inspite of being significant, improvement is still subtle. Hitiris et al., ${ }^{(10)}$ described a case of delayed ejaculation developed in a patient treated with daily pregabalin monotherapy in higher doses and for more prolonged time.

The increase in IELTS during use of pregabalin $150 \mathrm{mg}$ is not so long. Most of the patients received $75 \mathrm{mg}$ pregabalin showed no improvement. These results and Hitiris report may indicate that, efficacy of pregabalin in treatment of PE may be augmented with larger doses and more prolonged duration.

Wong and Malde, ${ }^{(9)}$ systematically reviewed the efficacy of on demand tramadol as a treatment option for PE. On demand oral tramadol increased IELTS between 4 and 13 folds in multiple different series. As tramadol is a weak $\mu$-opioid receptor agonist, concerns have been raised regarding the potential for drug dependence with the long-term ingestion of it, and this is the main reason limiting its more widespread use.

On demand dapoxetine therapy one hour prior to sexual act, showed a reasonable efficacy with a 3 - 4-fold increase of baseline IELT. Recently dapoxetine is proved to be characterized by high discontinuation rates of up to $90 \%$, mostly because of high side effects, cost issues, efficacy below expectations, and the need for scheduling sexual intercourse ${ }^{(\mathbf{1 1})}$

It is clear that both on demand tramadol and dapoxetine have more powerful efficacy than pregabalin. Pregabalin $150 \mathrm{mg}$ increases ejaculatory time 2-3 folds in most of the cases. However, tramadol and dapoxetine usage is still hampered by multiple issues.

As regard adverse events, it was minimal, not serious, tolerable, not sexually related and not lead to drug discontinuation. Bonnet and Scherbaum, (12) didn't find convincing evidence that pregabalin has an addictive power. Taking into consideration the small number of cases and short duration, we couldn't rely on this study to evaluate drug safety.

\section{CONCLUSION AND RECOMMENDATION}

This is the first report of an oral pregabalin used for the treatment of PE in men. On demand oral pregabalin $150 \mathrm{mg} 1-$ 2 hours prior to sexual relation, looks to be effective pharmacotherapy of PE. The effect of pregabalin is minimal and may be augmented with higher daily doses. Longerterm safety studies, and those comparing pregabalin with on demand tramadol and dapoxetine are essential to determine the place of pregabalin in the treatment of this distressing condition. 


\section{REFERENCES}

1. Porst H, Montorsi F, Rosen RC, Gaynor L, Grupe S, Alexander J): The Premature Ejaculation Prevalence and Attitudes (PEPA) survey: Prevalence, comorbidities, and professional help-seeking. Eur Urol; 2007, 51:816-24.

2. Waldinger MD: Premature ejaculation: Advantages of a new classification for understanding etiology and prevalence rates, Sexologies 2008, 17, 30-35.

3. Althof, S., Abdo, C., Dean, J., Hackett, G., McCabe, M., McMahon, C.: International Society for Sexual Medicine's guidelines for the diagnosis and treatment of premature ejaculation. 2009,http://www.issm.info/v4/. Accessed on 23 September 2011.

4. Byers ES and Grenier G): Premature or rapid ejaculation: Heterosexual couples' perceptions of men's ejaculatory behavior. Arch Sex Behav, 2003, 32: 261-70.

5. Waldinger MD, Zwinderman $\mathrm{AH}$, Olivier $\mathrm{B}$ and Schweitzer DH): Proposal for a definition of lifelong premature ejaculation based on epidemiological stopwatch data. J Sex Med; 2005, 2(4):498-507

6. Segraves $R$, Balon $R$ and Clayton $A$ : Proposal for changes in diagnostic criteria for sexual dysfunctions. J Sex Med;2007, 4(3):567-80.

7. Mohee $A$ and Eardley I: Medical therapy for premature ejaculation. Ther Adv Urol;2011, 3(5):211-22.

8. Tuken M, Kiremit MC, Serefoglu EC.Urology. Aug; 94:139-42. doi: 10.1016/j.urology.2016.04.036. Epub 2016 May 2.

9. Wong, B. L. K., \& Malde, S. The Use of Tramadol "On-demand" for Premature Ejaculation: A Systematic Review. Urology, 2013,. 81(1), 98-103.

10. Hitiris N, Barrett JA, Brodie MJ. Erectile dysfunction associated with pregabalin add-on treatment in patients with partial seizures: five case reports. Epilepsy Behav. 2006;8(2):41821.

11. Porst, H., \& Burri, A.Novel Treatment for Premature Ejaculation in the Light of Currently Used Therapies: A Review. Sexual Medicine Reviews. doi:10.1016/j.sxmr.2018.05.001

12. Bonnet, U., \& Scherbaum, N. How addictive are gabapentin and pregabalin? A systematic review. European Neuropsychopharmacology,2017, 27(12), 1185-1215.

How to cite this article: Al-Naggar M, EL Hariri M, Hashem A. Evaluation of Oral Pregabalin in Treatment of Premature Ejaculation. ZUMJ 2019; 25 (1); 126-131. 